\title{
Mongolians' Devotion to Gurus /Traditional and Contemporary/
}

\author{
Burnee Dorjsuren (Corresponding author) \\ Department of Mongolian Language and Linguistics \\ Division of the Humanities, School of Arts and Sciences \\ National University of Mongolia \\ E-mail: burneedorjsuren@gmail.com \\ Sainbayar Gundsambuu \\ Department of British and American Studies \\ Division of the Humanities, School of Arts and Sciences \\ National University of Mongolia \\ E-mail: sgundsam@fulbrightmail.org
}

\begin{abstract}
Received: 28-08-2015 Accepted: 19-11-2015
Advance Access Published: December 2015

Published: 01-03-2016

doi:10.7575/aiac.ijalel.v.5n.2p.17

URL: http://dx.doi.org/10.7575/aiac.ijalel.v.5n.2p.17

This article is supported by Language and Intercultural Communications Project, National University of Mongolia.
\end{abstract}

\begin{abstract}
From ancient times, Mongolians traditionally devoted themselves to their teachers. Could Mongolians still keep this tradition until today? Do they devote themselves to their teachers? If not, what are the causes and factors? This article aims to respond to these questions within the frame of sutras and books. This article is divided into two parts: the first part tells in detail about the guru devotion using the proverbs on guru devotion, one Mongolian folk oral monument, and other written monuments whereas the other one narrates how the process of today's globalization affects the tradition of Mongolians' devotion to gurus.
\end{abstract}

Keywords: oral and written monuments on teachers, relationship of tradition on guru devotion with Buddhist culture, a spiritual teacher, "Lamrim" (Stages of the Path) as a key monument on devotion to guru, present devotion to one's teacher

\section{Oral and written monuments on guru devotion}

Mongolians have a long and wonderful tradition of devoting themselves to their teachers since ancient times. In a record on relationship between guru and disciple by a military official from Ming Dynasty, China, it says, "Mongols call any person who could read and write a guru. This is the teacher. And the teacher names a learner as a disciple. This is the pupil. When the disciple starts learning how to read and write following his teacher, he bows to his teacher offering a sheep and an alcoholic drink. After he finishes his study, he expresses his gratitude to his teacher offering at least one gray horse and a white garment. The garment could be either cloth or silk depending on the financial situation of the disciple, and there is no specific amount.

Once a Mongolian is educated, he starts accompanying his lord wherever he goes and he is ranked rather higher than common people. Therefore, a teacher is highly respected in Mongolia (Bei-lo Fen-su, 1968, p.115). Analyzing the record in depth, it is understood that a person teaching is a guru, and a learner receiving the teaching is a disciple. When the learner is accepted as a disciple, he shows his great devotion to his guru and presents an offering to his guru once he finishes his study. An educated person is honored more as well.

There are many books written by Mongolians on proper discipline to be accepted by the guru. After carefully choosing a particular time on a special day, the learner is accepted as a disciple by the teacher. When the learner comes to his teacher, he must bring at least a silk and goods, or an animal from his herd depending on his wealth. On the Lunar New Year, he greets his teacher first (Dashnyam, 1974, pp. 49-58).

Mongolia is rich in proverbs on devotion to guru. A proverb about a person inevitably guided by a teacher when learning something, states, "a guru's mind contains thousands of substances whereas a hero's chest contains homeland." This means that a teacher only knows how to manage knowledge through a deep and narrow path. In another proverb about a person not able to go far without the guru's guidance, it teaches, "Do not consider a wise man with no guru as a knowledgeable, do not see a thing with no pattern as a thing."

In other words, a dress made without a pattern could satisfy human needs. However, it cannot be an exquisite garment. For a person who keeps distance from a teacher, or has no teacher makes a mistake and is lost, another proverb comes, "When the teacher is absent, the disciple controls the whole of something; when the lama is absent, the bonpo controls 
everything." On the other hand, if the teacher has a good teaching method, it is much more effective for the progress of disciples. The following proverbs express this: "If the teacher is not knowledgeable, the disciple is the same as the teacher." In contrast, "If the disciple is bad at his study, the teacher is bad, too." Like this, there are proverbs: "Disciple's knowledge is from the teacher." and "Disciple is the reflection of the teacher." These proverbs mean when the teacher is experienced in teaching, he has the power to make a good disciple. A good disciple is born because of a good teacher. Some Mongolian proverbs teach how it would be harmful if the disciple could not devote himself to the guru, or rejects him believing that he is not knowledgeable person. For instance, "Rejecting one's teacher results in expelling knowledge whereas refusing rice results in no food." This means that the main consequence of not devoting oneself to the guru is to be left behind without any knowledge.

The spread of Buddhism in Mongolia has enriched the Mongolians' devotion to guru with new concept (Boldbaatar, 2015). The Mongolian word "teacher" is associated with "buddha" and "lama" creating new expressions like "Buddha teacher" and "lama teacher". This is not a coincidence and a person who guides one down the path of good deeds and teaches how to be released from the suffering of the universe is honored as "Buddha teacher". When Mongolians panic they ask for mercy from the Buddha wispering "Oh, my Buddha teacher". Devoting oneself to lamas who are bearing a duty of learning Buddha's teaching and enlightening people is also believed that they could take ordinary people under their wing to liberate them from suffering. Mongolians devote themselves to the head of Tibetan Buddhism, the Dalai Lama. They listen to his teachings and try to use them in their daily life. The reason is that Dalai Lama truly tells the way of life. The Mongolian word "лам" is borrowed from Tibetan. It means "high" in Tibetan and came to Mongolian in 13th-14th century. In a Tibetan explanatory dictionary, this word is defined a "benevolent teacher". A well known Mongolist Kara. D. translated this word as a "teacher" in English. Mongolians have inherited a tradition of naming and respecting lamas who vow themselves to the service of Buddhism. In Mongolian sources it is recorded that even from 13th-14th century, Mongol khans invited head lamas of Tibetan Buddhism to their royal court to make them as lamas for sacrifice. A detailed reason of politics behind such relationship is not to be dicussed here. However, such kind of relationship is considered to be a proof of evidence that Mongol khans brought Tibetan lamas to decide the state affairs of their country and hear their teachings. In other words, the khans devoted themselves to lama teachers. In 17th-19th century when Buddhism was spread wide in Mongolia, hundreds of Buddhist temples and monasteries were estabished and Mongols sent their children to monasteries to make them disciples of lama. That time, monasteries were a center of education, and the reputation of both Tibetan and Mongol lamas was so high. Because, lamas taught Tibetan, the language of Buddhism, wrote their books and sutras in Tibetan in the field of all sciences to enlighten people. Besides, lamas were active not only in Buddhist activities but also in social life of Mongols. A lama teacher was the only one to teach the way of life from birth to death, correct wrong thoughts, cure others, help people to become educated, and guide them down the right path. Therefore, Mongols called lamas "teacher or guru" and uttered "pray for lama three treasures" and "pray for teacher". This shows how a lama teacher was reputed in both religious and civil society. This tradition went on until the beginning of 20th century or the political purge. It was a tragedy for the Mongolian society that hundreds of highly educated lamas were killed as victims of fraudulent ideology of that time. Slaughtering the lamas who were holding the great intellectual culture of Mongolia affected Mongolians break away from their traditional custom. On the other hand, it was cathostrophic that Mongolians forgot their traditional script which has been a national pride for a thousand years. Additionally, the Russian cyrillic alphabet was adopted. During the 70 years of Marxism and Leninism, there has been positive progress, and Mongolians have adopted western culture through Russian. However, the proudness of their own country has weakened and they tend to worship foreign culture. Fortunately, along with the reforms and changes in other countries, Mongolians' way of thinking has been restored as a result of the democratic movement in 1990s, and they had a wish and a desire to restore their former religion and culture. Since 1990, Mongolians have restored many temples that were destroyed before, decided to reuse their traditional script, and enacted a Law on Mongolian Language in 2015 as well. As a consequence, current Mongolians' devotion to guru is being revived.

From here, what type of custom: devotion to guru and what written in sutras and books would be considered. Among the monuments in Mongolian traditional script and Clear script, devotion to gurus was recorded a lot. In particular, the set of instructions "Lamrim" by Je Tsongkhapa /1357-1419/ includes a chapter "bshes gnyen bsten btshul" " or "Devotion to Spiritual Teacher".

The Tibetan word "bshes bnyen" is translated "spiritual friend or adviser" in Mongolian. This word is very formal word that honored a teacher as "virtue collector", "virtue supporter", and "virtue preferrer". "Spiritual" teacher is defined in the Lamrim as a person who "leads to the path of three scopes and guides to the great path to enlightenment" (Lamrim, 2005, p. 34). A spiritual teacher should obtain ten important qualifications. Those include a discipline ('dul ba), calmness (zhi ba), pacification (nyer zhi ba), knowledge exceeding (yon tan lhag pa), diligent (brtson bcas), rich of prophecy (lung gis phyug), meditate on the essence or secrets of religion (de nyid rab tu rtog pa), learned speaker (smra mkhas ldan), kind (brtse ba'I bdag nyid), and abandon a grief (skyo ba spangs). Since it is too difficult to see such qualified teachers in this harsh time, according to the Lamrim, at least one forth of them, or at most one eighth should have been qualified. On the other hand, it is said that the teacher should try to obtain those qualifications, whereas the disciple should seek a good teacher. Additionally, efforts of either the teacher or the disciple, in particularly, the teacher's self effort and the disciple's right choice are important.

As considered the devotion to guru, except the qualifications of teacher, qualifications of disciple including what qualifications the disciple should have, how the disciple devote himself to his teacher, what the advantage is, and disadvantage of non devotion to guru are explained in detail. Even though the teacher is well qualified, but the disciple 
is not so, no relationship would exist between them. Therefore, ideal disciple should have the following qualifications: an objective and straightforward (gzur gnas), intelligent and wise (blo ldan), and strive for endeavor (don gnyer ba). In addition, the disciple should show great respect toward his teacher and religion (chos dang chos smra ba la gus pa), and concentrate on subject dedicating all his heart (yid gtod pa) (Lamrim, 2005, pp. 38-39). A disciple who encounters an ideal and qualified teacher is fortunate enough. If an ideal disciple devotes himself to his teacher from the bottom of his true heart (bsam pas brten pa), he should do it through true relationship (sbyor bas). In the true faith, ten tendencies are important including listening to the teacher's teaching as an obedient child (bu mdzangs pa lta bu'I sems), creating a strong relationship with the teacher as an unbreakable vajra (rdo rje lta bu'I sems), and beng determined not to give up assignments given by the teacher (sa lta bu'I sems). In other words, it is emphasized that a proper attitude from the disciple towards the teacher creates a firm and reliable relationship between disciple and teacher. Moreover, another important factor is the thought to devote oneself to the guru. This means that the disciple must have a thought that our teacher is of the nature of the wisdom-knowledge of all the Buddhas, which they have manifested as him in order to lead us. Additionally, when imagining his teacher as a Buddha, the disciple must remind himself that his teacher, wisdom knowledge of Buddha is to lead us to the path to enlightenment. To understand the teacher's sole purpose it is much more beneficial to have such thought of devoting oneself to the guru. The disciple should think that the teacher's sole purpose is only for the well being of us, to release us from bad actions and to guide us to path to enlightenment. For the advantages of devotion to guru, the Lamrim tells "true faith is important for anyone who is bored of the universe and figures out that the life of universe is not necessary" (Lamrim, 2005, p. 42). Devotion is beneficial to think the teacher's help and kindness not his fault. If there is no devotion to the guru, the disciple will not understand the help and kindness of his teacher to guide him to the path of enlightenment, or he will have less chance to go on right way. This means "hold the teachings of the teacher but never hold his fault". Observing the teacher's fault does not mean that it is because of the teacher's fault, and viewing that "it is because of our sin" would be helpful not to hold a wrong thought about the teacher (Deed nomyn rashaany shim, 2011, p.77). As the Mongolian proverb "Mountan trees are high but short too", disciples who encountered their teacher are different and they treat their teacher differently. It depends on their knowledge, education and ethics but not on the teacher. A Tibetan reverend lama Ravdan taught that when the image, character and teaching style of the teacher seems not safisfying or faulty, do not hesitate, criticize or find any fault from the teacher. Because such image of the teacher seen to us is one of the reincarnations (Deed nomyn rashaany shim, 2011, p.78). In other words, the teacher is seen as a Buddha through an ordinary person at present time. Having this thought in one's mind would be beneficial to have a faith not to observe the teacher's fault but to receive the teaching that could liberate one from the sufferings of the universe. Therefore, it is not enough to forbid the disciple to find the teacher's fault, or criticize him. Devoting oneself to a guru means to have a faith in him. In the first page of a Mongolian sutra the word "namo guru" is usually written in Sanskrit. It means "pray for the teacher". Moreover, this tradition existed so that those who are opening the first page of a Buddhist sutra could understand its teachings after devoting themselves to a guru. After having faith in the teacher, respect will be born. Respecting one's teacher is clearly stated in the Lamrim. The reverend lama Ravdan says, "Not only devote oneself to the guru but also show enthusiasm to him. In doing so, a devotion to fulill the teachings will be created itself." (Deed nomyn rashaany shim, 2011, p.79) Regarding how the teacher is respected, the Lamrim explains it in the part of "devoting guru through relationship". It says making offerings to the teacher to make him happy is the first respect toward him and further, one should respect him physically or orally like "bathing him, massaging his body when he is sick, cleaning him, acompanying him, and practising what he teaches." For the teacher, it is not proper to have a desire to the offerings.

The above is an outline of devotion to guru in the Lamrim, source of theory on Tibetan and Mongolian devotion to guru. In the explanation of Lamim on the Mongolian devotion to guru, concepts of devotion to guru by Tsonkhapa were taken to be enriched through new examples and evidence (Bulgan, 2004, pp. 11-12). From the other side, Mongolian scholars have made many books and stories about praise and devotion to their guru. This is more proof of evidence that Mongolians inherited the heritage of respecting and devoting themselves to their teachers.

\section{Guru Devotion in Modern Mongolia}

Today Mongolia strives to broaden and strenthen its relationship with the world, further develop its technology and scientific findings and not be left behind the developed countries but to walk together with them as equals. Similarly, the government has started to implement development plans for Mongolia in the near and far future with the assistance from the international community towards its economy and society. Mongolia now meets the era of globalization after leaving the socialist ideology. Although it is good that people in this era declared freedom and independence, it has become difficult for poorly self developed and undisciplined people to find their own identities and place in the society. The number of Buddhists is decreasing while the number of followers in foreign religions including Christianity and Islam is increasing ("A report of 2004 survey," 2004). This trend brings up an important issue of national immunization, one of which is the guru devotion. At first it might seem as an issue of devotion to some teachers or lamas. However, in fact, guru devotion is tightly connected to the traditional belief system. While the Buddhist monasteries are not looking after the poor, the Christians are feeding and fulfilling their basic needs and gradually converting such people to their religion. This is not due to the low reputation of lamas. This is due to extensive and complex propoganda during socialism against Buddhism-Buddhism was portrayed as "dark drug against humans" which was deeply imbedded in movies and literature. For seventy years society described lamas as cruel and covetous oppressors. Mongolian children have become distant from their culture and tradition as more modern parents send their children to foreign kindergartens and schools from their young age. Foreign movies and programs dominate the media, and the programs that are suitable to children's age and interest with rich content of Mongolian culture, beliefs, and tradition are scarce. I agree with a 
German Mongolist scholar Barkman who wrote that Mongolians in the countryside kept their traditions and customs whereas the ones in urban areas veered towards foreign cultures (Barkmann, 2008, p. 329).

At primary, secondary and even higher schools foreign languages are taught widely and our young generation is pouring to learn from them. It opens the gate which the alien's culture freely enters in through the foreign languages, and moreover, it affects national cultue and custom diminish. As considered the devotion to guru, it has been common in civic educational organizations to tell bad words to teachers, insult, or criticize them instead of showing a respect toward them. Moreover, teachers are treated sometimes by the youth as a friend. It has been observed that young girls improperly treat wth their young male teachers whereas some older and reputable male teachers unethically treat with young female students. For those who believe in traditional Buddhism, it is different, and more ethics and devotion to guru they have. The above phenomenon seems to be related to what is said in Lamrim: a knowledgable and highly educated teacher with ideal disciple is rare. However, it is somehow affected by culural factors. On the other hand, it looks like even though both teacher and student communicate properly with each other in their native language, they still have some trouble understanding each other. It is because of their uprbinging and different level of education. Here is an exapmle. A Mongolian child who obtained his education in a Russian kindergarten and school in Mongolia looks he lives in Mongolia and is acquiring an education in his native country. But, he does not make contacts or friends with those born and educated in the countryside. This is originated from the culture difference. As for a teacher too, he struggles to understand students who were raised in foreign language environment even though he was born in the countryside and knows his tradition well. Such kind of teacher considers that the respect from students toward him is supposed to be so, but not devotion to guru. This is associated with that except from learning, a disciple is supposed to help in his teacher's private life and work. The help includes at least sawing, chopping wood, bringing water from the well or river, as well as making meals and doing other things the teacher requested. For those who were brought up in foreign language and cuture environment, in particular Russian language and culture, they can not devote themselves to a guru because of the lack of their knowledge about their tradition. In other words, it is difficult to establish a relationship between them. It is the opposite if the teacher is educated in Russia and the disciple graduates from a Russian school, it is much easier for them to understand each other.

There are conflicts between the relations of teachers depending on their childhood education and educational environment. For the National University of Mongolia in which I work, many teachers who obtined their education abroad, particularly in different cultural background, work for this school. There are misunderstandings between the teachers, as well as the young ones attitude toward older ones. I see that it is because of cultural difference. So, if teachers have understanding about "what cultural background the person has" they will be easily understand each other. Moreover, teachers will understand their students and the students will do so.

Not only among Mongolians but also in the communication of any country's people obstacles occur due to culture difference. For example, a foreigner who was going to be a disciple of a Tibetan teacher failed because he could not understand him (Relationship with spiritual teacher, n.d.). There was a language misunderstanding between them. In other words, the foreigner who does not know Tibetan could not communicate with the Tibetan teacher due to wrong translation of a book on devotion to guru. That book is the Lamrim by Tsongkhapa. A language contains a certain country's culture and due to lack of knowledge of the country's culture, people are not able to communicate with each other.

To become a disciple of a Mongolian teacher, a foreigner, especially those who are from non Buddhist country should know the Mongolians' devotion to guru. If so, it will be a foundation of a good and strong relationship with the teacher. In terms of peoples in Asia they have an ancient bond of religion and culture. Therefore, lots of similarities are there regarding respect of older people and tradition of respect. So, it is comparatively easy to make a relationship between teacher and student. As opposed it to people in different culture and religion, it is more difficult.

When considering the relationship between a teacher and a disciple, it is important to account for the time and social peculiarity to some extent. Leaning to one side causes a difficulty in establishing a proper relationship. For example, there are two types of leaning to one side. The first one is that if a wrong action from the teacher, such as an attitude of insult and abuse comes, the disciple ceases the relationship. The other one is to justify every single wrong attitude from the teacher (Relationship with spiritual teacher, n.d.). Any difficulty in communication is caused by a different attitude to follow one's own culture. A Mongolian proverb, states "If you drink the water, follow the custom." Therefore, those who are studying abroad and being surrounded by other cultures should learn from the tradition and custom of that place. In addition, they should make an effort to study their own traditional custom, use it in their daily life, learn from other cultures and understand them well. This is essential to create good communication and relationships.

\section{Conclusion}

Mongolians' devotion to guru is closely connected to Buddhism. Traditional Buddhism played an important role in Mongolians' faith in loving others, respecting elders, specially teachers, understanding the meaning of life and becoming a kindhearted and educated person. Therefore, it is required to consider the devotion to guru within the Buddhist books and sutras. When Buddhism was spread, this faith was strong. In contrast, the faith diminished during socialism when Buddhist lamas were killed and culture and education centers: monasteries and temples were destroyed. Since the democratic movement in 1990s, the faith has been restored. To talk about devotion to gurus, first we should consider the devotion to a lama - teacher. The reason is that in the Mongolian society lamas were bearing a duty to enlighten and educate people that time. They actively participated in the social life as well. On the other hand, Buddhist belief was strong in the civil society. Devotion to guru in Buddhism played an important role in close and strong 
relationship between teacher and disciple. Devoting oneself to a guru means having faith in a teacher from the perspective of Buddhist culture. Today traditional Buddhism revived and Buddhist teachings satisfy people's intellectual needs. However, it can not cover the whole population. It is because of the wide spread of other religions like Christianity and Islam. Today the Mongolans' Devotion to Guru exists under current globalization and multicultural influence. Although the faith is taking its way of restoration, it is still difficult to predict if it will exist firmly in the future. At least, if Mongolians keep the traditional faith longer, there is more of a chance to the spread of devotion to guru.

\section{References}

A report of 2004 survey on temples, churches and religious organizations in Ulaanbaatar (n.d.). Retrieved from ubstat.mn [According to statistics in 2004, out of 372 temples and churches operating in Ulaanbaatar, 228 are Christian and 106 are Buddhist. A total of 4577 volunteers were registered in temples and churches which have permission of operation in the capital city. 4115 of them were from Christianity whereas 167 were from Buddhism. Before 1990 there was almost no other faith except Buddhism.]

Bayansan, J. (2002). Soyol, xel, u'ndestnii setgelgee [Culture, Language, and National Thoughts]. Ulaanbaatar.

Bayasgalan, Sh. (2011). Burxany shashind orox uud [The Gate to Buddhism]. Ulaanbaatar.

Bei-lo Fen-su. (1968). Mongolyn zan zanshilyn temdeglel [Records of Mongolian Custom and Tradition]. In Su'xbaatar,G., \& Jamsran,L. BNMAU tuuxiin deej bichig. (Vol.1). [Anthology of MPR History]. (p. 115). Ulaanbaatar. Bira, Sh. (1994). Mongolyn tuux, soyol tuux bichlegiin sudalgaa [Research on Mongolian history, culture and history writing]. Tokyo.

Boldbaatar, J. (2015). Mongolyn burxan shashin daxi bagsh, shaviin barildlaga: Mongolyn buddyn sudlalyn orchin u'yeiin asuudal, dursamj iltgeliin emxtgel [The bond between teacher and disciple in Mongolian Buddhism: A compilation of contemporary issues, memories and lectures in Mongolian Buddhism studies]. (pp. 93-102). Ulaanbaatar.

Bulgan, T. (Trans from Tibetan). (2004). Bodi mo'riin zereg [Lamrim]. Ulaanbaatar.

Choimaa, Sh. (2011). Mongol yos zanshil, ulamjlalt uxaanaa zaan surgagch nart tus dem [The Contribution to teachers of Mongolian custom and traditional way]. Ulaanbaatar.

Dashnyam, A. (1974). U'lziinarangiin O'chil [Ulziinaran's Confession]. Ulaanbaatar.

Erdem shinjilgeenii bu'teeliin chuulgan. (5th ed.). (2012). Mongol bichgiin xelnii zui, terguun devter, udirtgal (B.Rinchen) [Introduction of Grammar of Mongolian Traditional Script]. (1st ed.) Ulaanbaatar.

Mnyam med tsong kha pa chen pos mdzad pa'I byang chub lam rim che ba bzhugs so. (2005). [The Great Treatise on the Stages of the Path to Enlightenment Taiwan]. Taiwan.

Mongol daxi Ix Xo'lgo'nii ulamjlalyg xadgalax to’v. (2011). Deed nomyn rashaany shim (Gevsh lamtan Ravdan) [The Essential Nectar]. Ulaanbaatar.

Ju'gder, Ch. (1987). Mongold fyeodalism togtox u'yeiin niigem-uls to'r, gu'n uxaany setgelgee (ertnees XIV zuun xu'rtel) [Sociopolitical and philosophical thoughts during feaudalism in Mongolia]. Ulaanbaatar.

Ju'gder, Ch. (1972). XIX-XX zuuny zaag daxi mongolyn niigem-uls filosofiin setgelgeenii xo'gjil [Development of Mongolian socio-political and philosophical thoughts between 19th-20th century]. Ulaanbaatar.

Purevjav, S. (1978). Mongol daxi sharyn shashny xuraangui tuux [Brief History of Buddhism in Mongolia]. Ulaanbaatar.

Relationship with Spiritual teacher in two lifetimes. (n.d.) Retrieved from http://www.berzinarchives.com/web/en/index.html

Rinchensambuu,G. (2012). Mongol zuir cecen u'g, terguun, ded devter [Mongolian Proverbs]. (1st \& 2nd eds.). Ulaanbaatar.

Suxbaatar, G., \& Jamsran, L. (1968). BNMAU-yn deej bichig. (Vol. 1) [The Anthology of MPR]. Ulaanbaatar.

Barkmann. U. B. (2008). Orchin cagiin mongolyn tuxai o'guulluud [Stories on Modern Mongolia]. Ulaanbaatar.

U'lgeriin dalai. (2014). [The Ocean of Tales]. (Bu'rnee, D., \& Enkhto'r, D. Transliterated from Mongolian old script to Modern Cyrillic). Ulaanbaatar.

Vostrikov, A.I. (2015). To’vd xeleerxi tuuxiin zoxiol [Historical stories in Tibetan] (Bu'rnee, D. Trans.). Ulaanbaatar. 